\title{
Coupled Adaptive Fuzzy Control of Nonlinear, Time-Varying Plant
}

\author{
Raimundas LIUTKEVIČIUS \\ Vytautas Magnus University \\ Vileikos 8, LT-3035, Kaunas, Lithuania \\ e-mail: r.liutkevicius@if.vdu.lt
}

Received: May 2003

\begin{abstract}
This paper analyses coupled control of a nonlinear, time-varying plant. Uncoupled and coupled direct adaptive controllers, based on fuzzy logics, are synthesized to control the water level and the air pressure in a closed tank. The satisfactory efficiency of the controllers is experimentally demonstrated running the plant under the different working conditions. Coupled fuzzy controllers are compared with the uncoupled fuzzy controllers.
\end{abstract}

Key words: nonlinear plant, fuzzy logic control, direct adaptive fuzzy control, coupled fuzzy control, rule base, level and pressure control.

\section{Introduction}

Water level and air pressure control is a classical problem in control engineering, specific to the rectification, adsorption, and graduation technological processes, widely found in chemical and food industry. Most articles analyze simple water level control systems, where no additional forces affect the water flow, and plants' configurations are technologically simple (Ogata, 1997; Driankov, 1998; Abonyi, 2003). According to the physical laws, simplified linear mathematical models are defined for those plants and then model based control methods are synthesized. The control problem becomes more complex if the control of water level and air pressure is considered in one system. In such a case the change of water level or air pressure set point changes the dynamics of the whole system what requires the adaptation of controller parameters. When water flows through pipes, the dirt gathers on its inner sides, decreasing its inner diameter and herewith the amount of flowing water per time unit. This feature also changes the dynamics of the flow system and stipulates an adaptation of controller parameters. In this article the effect of such phenomenon on control system is also analyzed.

For more precise control of the plant, coupled direct adaptive fuzzy control method is synthesized. This control method is an improvement of the fuzzy control method, provided in the earlier articles (Kaminskas and Liutkevičius, 2002). The primary control problem, considered with this control system, is regulating both the water level and the air pressure at the specified set points. The secondary problem is that of decreasing the 
overshoot during the system's transient response and the third problem is to decrease the variations of the manipulated variables, as they affect the useful life-time of physical devices, in this case water and air pumps.

\section{The Plant}

The plant's scheme is shown in Fig. 1. Its central part is a close tank with adjustable water level and air pressure. The variables of the process "pressure" and "level" can be varied using the inlet water flow and/or the inlet airflow. These are varied with separate pumps $(1,2)$. The pumps are the actuators and have an electrical input-range of 0 to $10 \mathrm{~V}$. The tank has two outlets for water flow and two outlets for airflow. The manual valve (5) and/or the combination of the magnetic valve (4) and manual valve (4a) control the exit water flow. These valves and the control of the water pump manipulate the stationary condition of water flow. The manipulating of pressure is performed through control of the valves $(6,6 a, 7)$ and the air pump (2). Air chamber (3) increases the time constant of the pressure loop and equalizes pulses in the airflow. The water flows in and out of the tank through rubber hoses, what are circled in rings. This water flow peculiarity increases plant's nonlinear characteristics. The pumps have dead zones of different magnitudes and saturation non-linearity; they introduce electrical noises and delays into the system. The water flow depends on the water temperature and its softness. These characteristics influence the water flow resistance. The change of level and pressure set points itself changes the dynamics of the plant. This is because the water level and the air pressure are dependent on each other, so that the change in the air pressure affects the water level, whereas the change in the water level affects the air pressure. This is obvious as the decrease in the air pressure means that less force acts on the water and less power is needed to keep the water at the desired level. The change of the water level changes the size of the tank area, left for the air, and the less the area the less the power is needed to keep the pressure at a given set point.

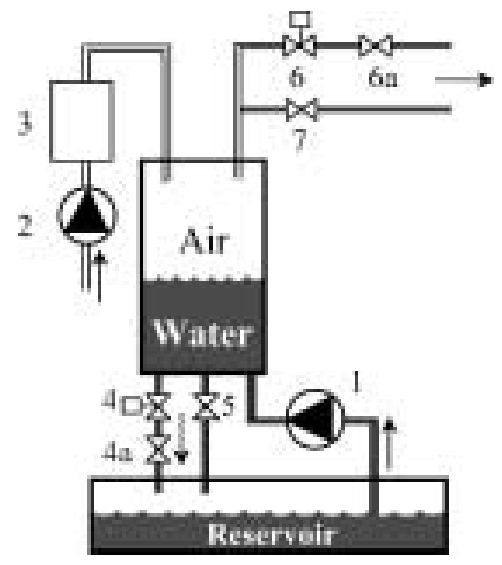

Fig. 1. Plant's scheme. 


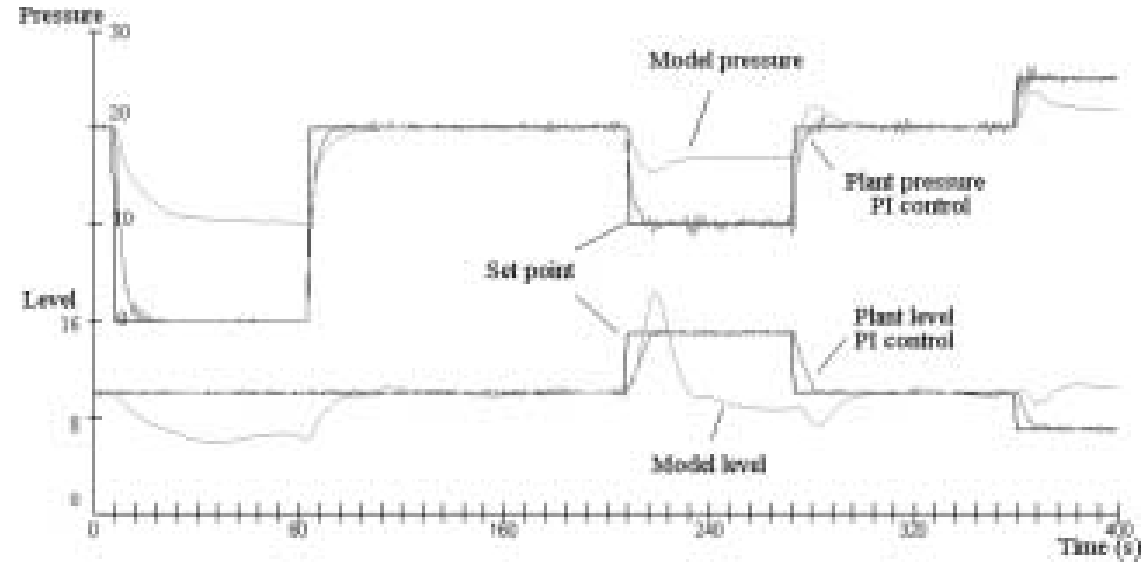

Fig. 2. Comparison of the plant output and the output of its model.

\section{Plant's Linear Model}

The linear mathematical model for this plant was derived in order to approximately describe the physical processes in it (Kaminskas and Liutkevičius, 2002). The response of the plant and its mathematical model to the different set points is shown in Fig. 2.

From the Fig. 2 it is seen, that the plant's model output corresponds to the actual plant's output only at the set point for which it was designed - the water level at $10 \mathrm{~cm}$, the air pressure at $20 \mathrm{mbar}$. Any change of any of the set points brings the discrepancy to the mathematical model. This proves that the process is non-linear, and that for any other set point it is necessary to recalculate the model's parameters. Besides, this model is simplified by ignoring saturation effects, water flow friction non-linearities, and other characteristics, that make noticeable influence to the actual process.

Complex, non-linear nature of the plant, tight relationship between the sub-processes in the time-varying plant, and not accurate enough its mathematical model induced to use fuzzy logic to control this plant.

\section{Water Level and Air Pressure Fuzzy Control}

For the control of the water level and the air pressure in the closed tank uncoupled adaptive fuzzy controllers are synthesized (Kaminskas and Liutkevičius, 2002). These controllers give evidently better performance than the conventional PI and PID controllers, but the main their drawback is that in the transient operating modes the air pressure performs big overshoot. This is because the water level and the air pressure are controlled in the same tank. These sub-processes are actually closely related to each other, and meanwhile, the synthesized uncoupled adaptive fuzzy control methods do not take into account these interrelations and control the processes separately. The drawback affects the air pressure more than the water level because the air pressure is much more sensitive to control signal variations that the water level. To eliminate the drawback a coupled 
direct adaptive air pressure fuzzy controller is synthesized. For the control of the water level, uncoupled adaptive fuzzy controller is used (Kaminskas and Liutkevičius, 2002).

\subsection{Uncoupled Adaptive Fuzzy Control}

For the control of the water level and the air pressure two separate adaptive fuzzy controllers were first synthesized. The structure of two controllers is identical, but the parameters are different. The structure of the controller is shown in Fig. 3.

\section{Controller's inputs and outputs}

Adaptive fuzzy controller has four inputs and one output. The input signals are: the actuating error $e(t)=r(t)-y(t)$, linguistically named "le" and " $s e$ " for the water level and the air pressure respectively, the change of controlled variable $c(t)=\mathrm{d} / \mathrm{d} t y(t)$ linguistically named " $l c$ " and " $s c$ " for the water level and the air pressure respectively, the reference signal of the controlled variable $r_{1}(t)$ and the reference signal $r_{2}(t)$ of the other sub-process. The water level reference signal is linguistically named " $l$ ", and the air pressure - " $s$ ". The reference inputs are used to identify the plant's operating mode.

Linguistic variables are described using the triangular form membership functions. The "effective" universes of discourse for the water level, the air pressure errors' and the changes of errors' linguistic variables are defined by experiment, taking into account the dynamical characteristics of the plant. For water level actuating error the effective universe of discourse is $[-2.2,2.2]$, for the change of error linguistic variable $-[-0.33$, $0.33]$, for the air pressure actuating error linguistic variable $-[-5.0,5.0]$, and $[-1.09$, 1.09] - for the change of error linguistic variable. The "effective" universes of discourse for reference signals' linguistic variables are chosen taking into account the plant's physical parameters, so for the water level linguistic variable the universe of discourse is set to $[0.0,25.0]$, for the air pressure linguistic variable - $[0.0,50.0]$. The "effective" uni-

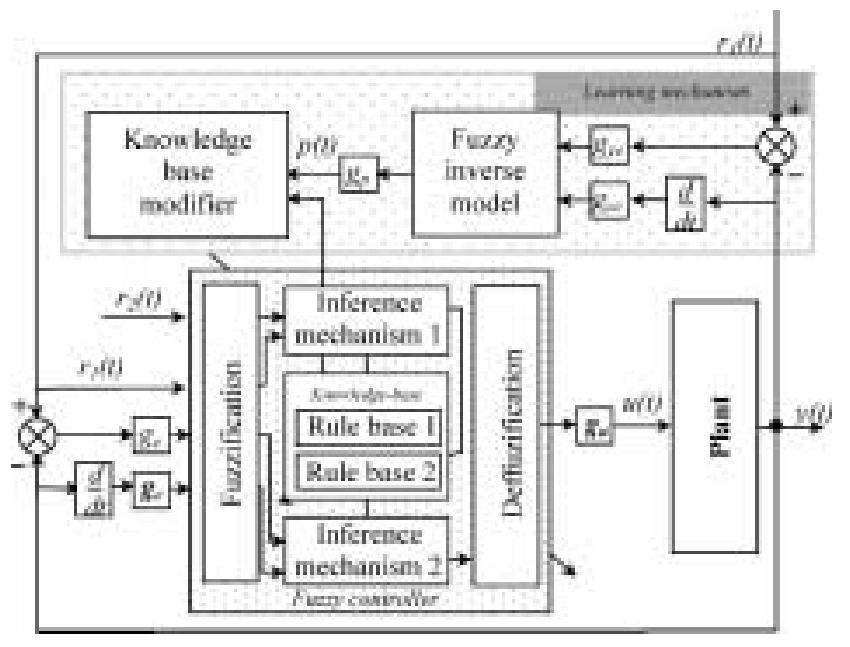

Fig. 3. Uncoupled, adaptive fuzzy controller. 


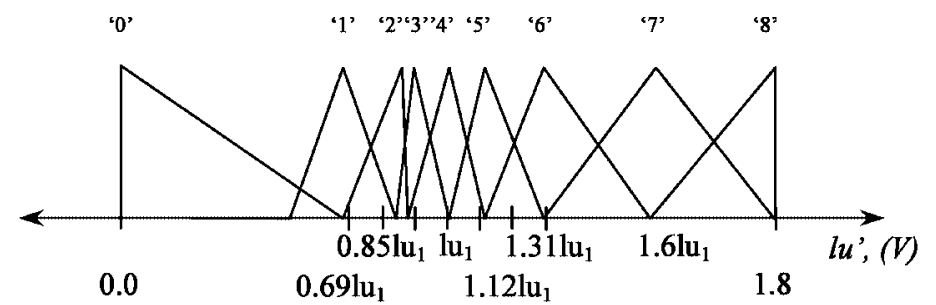

a)

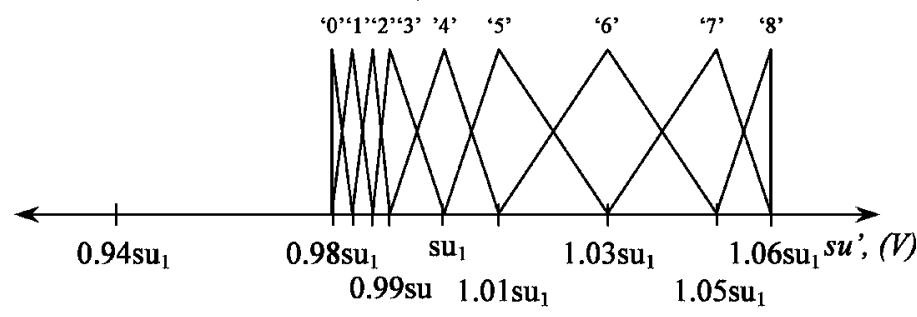

b)

Fig. 4. Basic outputs' membership functions defined for a) the water level, b) the air pressure.

verses of discourse of the output linguistic variables are chosen taking into account the physical characteristics of actuating mechanisms (the control signal can take values from the interval $0-10 \mathrm{~V})$, so it is $[0.0,10.0]$. According to the defined effective universes of discourse scaling gains are chosen so, that input universes of discourse are normalized to intervals $[-1 ; 1]$, and the output - to interval $[0,1]$.

The linguistic variable of the actuating error is made of nine linguistic values, the change in error, and reference inputs - of seven values. The linguistic values of the second inference mechanism are calculated on-line, using the basic, defined in advance, nine linguistic values, that vary depending on the values $u_{1}(t)$ of the first inference mechanism (Fig. 4).

\section{Rule bases}

Adaptive uncoupled fuzzy controller has two rule bases. The rules in the rule-bases have a linguistic form:

$$
\text { IF } \tilde{u}_{1} \text { is } \widetilde{A}_{1}^{j} \text { AND } \tilde{u}_{2} \text { is } \widetilde{A}_{2}^{k} \text { THEN } \tilde{y} \text { is } \widetilde{B}^{p} \text {, }
$$

where $\tilde{u}_{1}$ and $\tilde{u}_{2}$ are linguistic variables, coherent with the input variables, $\widetilde{A}_{1}^{j}$ and $\widetilde{A}_{2}^{k}-$ linguistic values of the appropriate linguistic variables, $\tilde{y}$ - linguistic variable, composed of $\widetilde{B}^{p}$ linguistic values, coherent with the output variable. The propositions in the rules are connected with each other using fuzzy logical operator AND (minimum operator).

The fist rule base links the reference signals with the basic control signal value and is made of forty-nine rules. These rules are adjusted by the learning mechanism. The rules of the second rule base specify the value of the output depending on the current values of the actuating error and the change of the controlled variable. This rule base is re-formed every time the reference signals are changed, so depends on the first inference mechanism. The 
second rule base has sixty-three linguistic rules whose conclusion membership function centers are calculated according to formula:

$$
c_{i j}=b_{i} *(1-(s k *(3-j))),
$$

where $c_{i j}$ is the center of the area of the output's implied fuzzy set, $b_{i}$ - the center of area of the defined in advance $i$ th basic output membership function (Fig. 4), the index $i$ is related with the linguistic-numeric value of the actuating error, $j$ is related with the linguistic value of the controlled variable, and $s k$ defines of what percent amount to correct calculated output membership function center. In the water level controller $s k$ is set to 0.06 , in the air pressure controller - to 0.0004 . Actually, the controller's second inference mechanism stores only nine rules. They describe what control signal must be when the controlled variable does not vary. These nine rules (the centers of output membership functions) are adjusted by the adaptation mechanism. The other rules are formed and evaluated on line. At the start up of the controller the assumption is made that the controller knows nothing about how to control the process.

\section{The process of deffuzification}

For the calculation of the crisp output values both inference mechanisms use center of average deffuzification method (Passino, 1998). The output of the second inference mechanism is the output of the controller.

\section{The learning and adaptation mechanisms}

The learning mechanism provides the controller with the capability to remember the rules of the operating modes, learnt during the control of the process. The learning mechanism adjusts the rules in rule base of the first inference mechanism, modifying the information about the values of the control signal that are used to control the plant at the appropriate operating mode. If two operating modes are learnt, the control rules for any other unexplored operating mode are approximately calculated using the values of the adjacent learned operating modes. This makes the final adaptation process much faster. According to the adjustments, made to the rules, the learning mechanism tracks for the changes in the plant's parameters. If such a change is noticed, the mechanism corrects all the rules in the first rule base. Also, the learning mechanism supervises the learning process and allows speeding it up at the start up of the controller.

The purpose of the adaptation mechanism is to correct the second rule base in order to possibly reduce the actuating error. The adaptation mechanism consists of two parts: the fuzzy inverse mechanism and the knowledge base modifier. The fuzzy inverse mechanism is a separate fuzzy system that maps the actuating error and the change of the controlled variable to the necessary changes in the process inputs. The fuzzy inverse model has its own static rule base, shown in Table 1.

The rule base consists of static sixty-three rules that describe all the possible combinations of the linguistic inputs linguistic-numeric values. The numbers in the table define the centers of areas of the output membership functions. The propositions of the rules are evaluated using fuzzy logic operator $A N D$, the crisp output is calculated using center of 
Table 1

The rule-base of the adaptation mechanism

\begin{tabular}{|c|c|c|c|c|c|c|c|c|c|c|}
\hline & \multicolumn{9}{|c|}{ Actuating error "ye" } \\
\hline & & “ $0 ”$ & $" 1 "$ & “2” & “3” & "4" & "5” & $" 6 "$ & "7" & "8" \\
\hline \multirow{7}{*}{$\begin{array}{l}\text { Change of the } \\
\text { actuating } \\
\text { error "yc" }\end{array}$} & " $0 "$ & -0.70 & -0.60 & -0.50 & -0.40 & 0.00 & 0.00 & 0.00 & 0.00 & 0.00 \\
\hline & "1" & -0.60 & -0.50 & -0.40 & -0.30 & 0.00 & 0.00 & 0.00 & 0.00 & 0.00 \\
\hline & "2" & -0.50 & -0.40 & -0.30 & -0.20 & 0.00 & 0.00 & 0.00 & 0.00 & 0.00 \\
\hline & “3” & -0.40 & -0.30 & -0.20 & -0.10 & 0.00 & 0.10 & 0.20 & 0.30 & 0.40 \\
\hline & "4" & 0.00 & 0.00 & 0.00 & 0.00 & 0.00 & 0.20 & 0.30 & 0.40 & 0.50 \\
\hline & $" 5 "$ & 0.00 & 0.00 & 0.00 & 0.00 & 0.00 & 0.30 & 0.40 & 0.50 & 0.60 \\
\hline & "6" & 0.00 & 0.00 & 0.00 & 0.00 & 0.00 & 0.40 & 0.50 & 0.60 & 0.70 \\
\hline
\end{tabular}

gravity method (Cheng, 2001). The output of the fuzzy inverse model is gained with the gain $g_{p}$, which in case of water level control is set to 0.0125 , and in case of air pressure control -0.00825 . This gain defines the adaptation speed. The knowledge base modifier adjusts the rule base of the controller's second inference mechanism, specifically the nine rules, describing the output signal's value according to actuating error, and assuming that the controlled variable does not vary. As the other rules are calculated on line from these nine, so any change in these nine affect all other rules. The knowledge base modifier is complimented with the adaptation supervisory algorithm that tracks the process of adaptation and does not allow the rule base modifier to correct the rules if the corrections violate the order of the output membership functions (the centers of the areas of the membership functions must be in a rising order). If the knowledge base modifier seeks to correct the rules, but the corrections are restricted, then all the nine rules are modified simultaneously. In all other cases knowledge base modifier corrects only those rules that influenced the output at the previous program cycle.

\subsection{Coupled Adaptive Air Pressure Fuzzy Controller}

Coupled air pressure fuzzy controller is synthesized to improve the control of the air pressure in the tank. The control signal here is calculated taking in to account the water level in that same tank, controlled with uncoupled adaptive fuzzy controller. The structure of the coupled adaptive fuzzy controller is shown in the Fig. 5.

Controller's inputs and outputs

The air pressure coupled adaptive fuzzy controller has five inputs and one output. The input variables are the air pressure and the water level reference signals $\operatorname{sr}(t)$ ir $\operatorname{lr}(t)$, respectively, the air pressure actuating error $s e(t)$, the change of the air pressure $s c(t)$ and the water level actuating error $l e(t)$. The output is the air pressure control signal. The same linguistic variables and their linguistic values are defined for the inputs and the outputs as are used in the air pressure and the water level adaptive fuzzy controllers. The gains for the inputs of the coupled adaptive fuzzy controller are set to the following values: $g_{s e}=0.55, g_{s c}=3.0, g_{l e}=0.5$. The linguistic values of the output's linguistic 


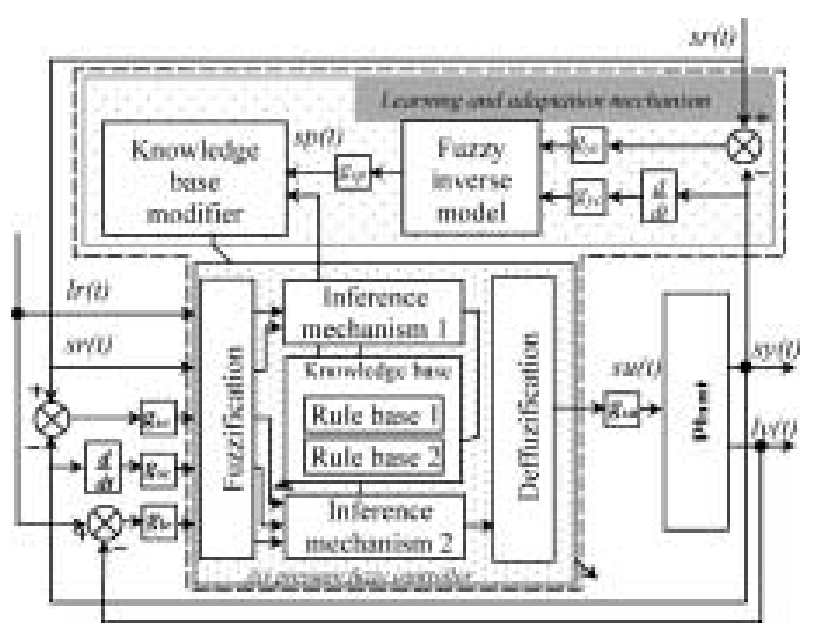

Fig. 5. Coupled adaptive fuzzy controller for air pressure.

variable are formed on-line from the basic nine linguistic values, defined in advance. These nine linguistic values are dependent on the output of the controller's first inference mechanism. The gain of the controller's output $g_{s u}$ is set to 10 .

The inputs of the learning mechanism are the air pressure actuating error and the change of air pressure; the output is the value of the adjustment of the rules (the centers of the outputs of the rules membership functions), defined in the second rule base. The linguistic variables, assigned to the inputs of the learning mechanism are used the same, with the scaling gains $g_{y e}=0.45$ and $g_{y c}=3.0$. The scaling gain $g_{s p}$ for the output of the fuzzy inverse model is set to 0.0008 .

Rule bases

Coupled air pressure adaptive fuzzy controller is supplemented with the additional input - the water level actuating error. This input, along with the air pressure actuating error and the change of air pressure, is used to calculate the air pressure control signal. The input is evaluated with the controller's second inference mechanism, so it's rule base is extended to five hundred sixty seven rules that evaluate all the possible combinations of the inputs' linguistic values. The rule base of the first inference mechanism, that calculates the basic control signal value, has forty-nine rules.

The rules of the second inference mechanism are calculated online from the nine basic output's membership functions, according to formula:

$$
c_{i j z}=b_{i} *\left(1+k_{-} l e[z]\right) *\left(1-k_{-} s c[j]\right),
$$

where $c_{i j z}$ is the center of area of the ijz rule's output's implied fuzzy set, $b_{i}$ - the center of area of the defined in advance $i$ th basic output membership function, the index $i$ is the linguistic-numeric value of the air pressure actuating error's linguistic variable, $j$ is the linguistic-numeric value of the change of air pressure input's linguistic variable, and $z$ is the linguistic-numeric value of the water level actuating error's linguistic variable. 
The array $k_{-} l e[]=\{0.22,0.165,0.11,0.025,0.0,-0.025,-0.06,-0.09,-0.12\}$ is the array of numbers, that are used to shift the centers of areas of the basic output membership functions $b_{i}$ depending on the water level actuating error's linguistic value, the array $k_{\_} s c[]=\{0.0012,0.0008,0.0004,0.0,-0.0004,-0.0008,-0.0012\}$ is the array of numbers, that are used to shift the centers of areas of the basic output membership functions $b_{i}$ depending on the change of air pressure linguistic value. The values in the arrays $k_{-} l e[]$ and $k_{-} s c[$ [] affect the air pressure transient mode's characteristics, such as speed and shape. The arrays $k_{\_} l e[]$ and $k_{-} s c[]$ are chosen in such a way, that the control rules of the second inference mechanism are constructed so that the air pressure does not reach the reference value faster then the water level reaches its reference value, what allows to avoid air pressure overshoots during the transient operating modes.

\section{The Analysis of the Control Methods}

The performance of the water level and the air pressure control methods is experimentally tested operating the plant under: 1) normal conditions, when the water and the air outlets are fully open, and 2) reduced conditions, when the water and the air flow outlets are reduced in half, what imitates the reduction of the pipes due to the dirt, that gathers on the inner side of the pipes and on filters. The purpose of the experiments is 1) to evaluate the effectiveness of the water level and the air pressure controllers, 2) to evaluate the effectiveness of adaptation and learning capabilities of fuzzy controllers, 3) explore the capability of the controllers to regulate coupled and time-varying processes.

For the analysis of the control methods, 400 seconds of data are taken from each of the experiment, starting from the first pair of set points, defined in the reference signal. The set points are changed every 57 seconds; the data from the plant are collected at onesecond intervals. The water level reference signal has a step form with the steps at 8,11 , $14,17,12.5,9.5$, and $8 \mathrm{~cm}$, the air pressure reference signal has steps at $4,8,16,24,20$, 12 , and $4 \mathrm{kN} / \mathrm{m}^{2}$ (or $\mathrm{kPa}$ ). The reference signals for the water level and the air pressure are changed simultaneously so the overall reference signal is the pairs of both reference signals: 8-4, 11-8, 14-16, 17-24, 12.5-20, 8-4.

The comparison of the uncoupled fuzzy controllers with the conventional PI and PID controllers is shown in (Kaminskas and Liutkevičius, 2002). The experiments show, that the uncoupled fuzzy controllers have an advantage over PI and PID controllers. As the performance of coupled adaptive fuzzy control methods improves the control of the plant, these methods are compared only with the uncoupled fuzzy control methods.

\subsection{The Criterions}

The efficiency of the control methods was analyzed in every operating mode, defined by the reference signal, calculating the population standard deviations of controlled and control signals for: a) the stationary processes, b) the transient modes, and c) the whole 
process (400s). The calculations are made for the same number of measurements according to formula:

$$
\sqrt{\frac{1}{N} \sum_{i=1}^{N}\left(x_{i}-\bar{x}\right)^{2}}
$$

where $\bar{x}$ is 1) the reference signal, when calculating the deviation of the controlled variable, and 2) the average of the control signal

$$
\bar{x}=\frac{1}{N} \sum_{i=1}^{N} x_{i}
$$

when calculating the deviation of the control signal.

\subsection{Graphical Representation of the Experiments}

The response of the plant, controlled with adaptive fuzzy controllers, to the step form reference signal is shown in Fig. 6. The graphs represent two operating conditions: a) normal and b) when the outlets of the plant are reduced. Fig. 7 shows the control of the plant using coupled adaptive fuzzy controllers.

Each graph is split into two parts: the uppers part shows air pressure control, and the lower graph - water level control. Gray curve in each part represents the control signal; other curves are the reference signal and the plant output.

\subsection{Effectiveness of the Control Methods}

The effectiveness of the control methods is determined calculating the standard deviations of a) the controlled signals and b) the actuating errors. The calculation results are presented in Fig. 8, and explained bellow.

Water level and air pressure direct uncoupled adaptive "fuzzy" control methods. It is experimentally shown that water level and air pressure are controlled more effective with adaptive fuzzy control methods when with conventional PI and PID methods. The adaptive fuzzy controllers are capable to adapt to the time-varying plant, maintaining the satisfactory control efficiency. After the change of the plant's working conditions, the average water level actuating error at different set points makes $1.3 \%$ of the set point values and is average 14.4 and 30.1 times smaller than that of PI and PID controllers. The average of the water level control signal deviation makes $11.9 \%$ of the average control signal value and is average 14.7 and 17.8 times smaller, than that of PI and PID controllers'. The average air pressures actuating error, when the plant's working conditions are changed is $1.4 \%$ of the set point value and is average 3.3 and 4.2 times smaller, than that of PI and PID controllers'. The average air pressures deviation, operating the plant at different set point is $1.8 \%$ of the set point values and is also smaller than PI and PID controllers' control signals deviations average 12.6 and 7.8 times, accordingly. 
Air pressure direct coupled adaptive "fuzzy" control method. This method is synthesized in order to improve the water level and the air pressure control during the transient operating modes - to decrease the air pressure overshoot in transient modes. Coupled adaptive fuzzy control method transfers the plant from one operating mode to the other over the longer time interval, but the transient characteristics are more qualitative than in case when the plant is controlled using the uncoupled fuzzy control methods. The overall control efficiency, if compared with uncoupled adaptive fuzzy control methods, is average 1.3 times better.

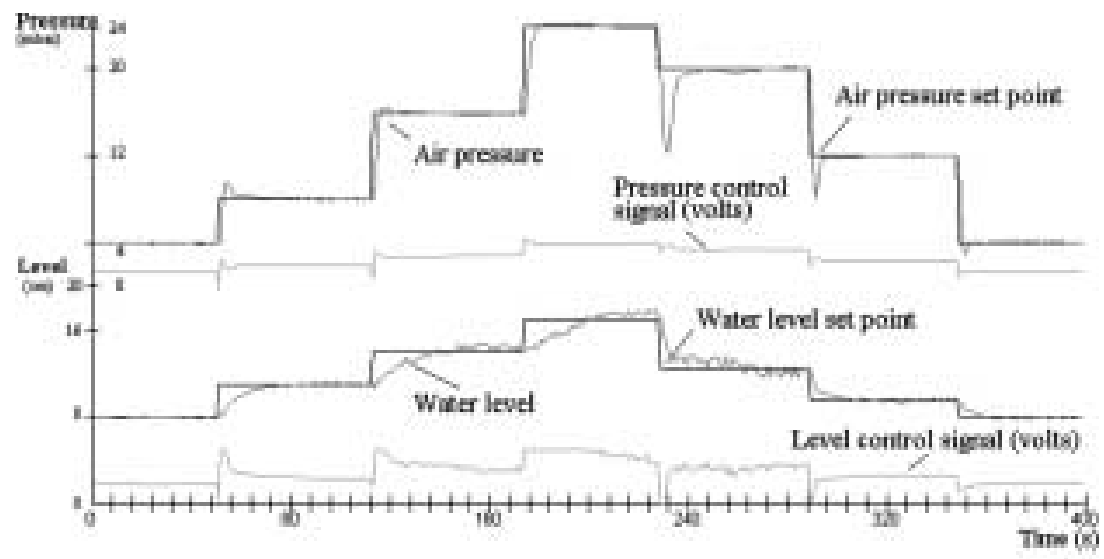

(a)

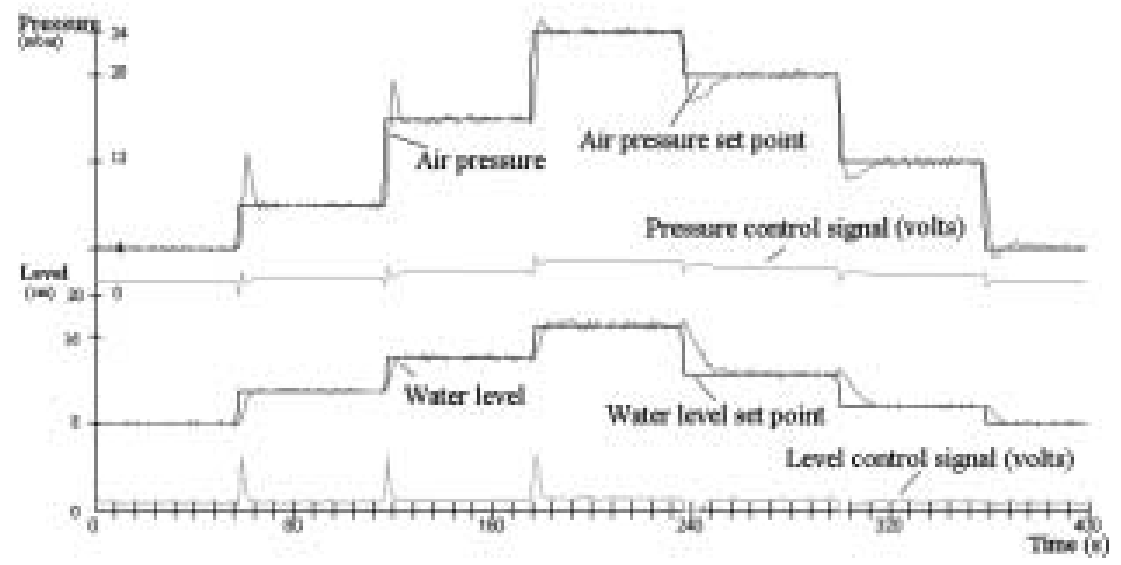

(b)

Fig. 6. Water level and air pressure direct uncoupled adaptive fuzzy control (a) normal plant operating conditions, (b) reduced outlets' throughput conditions. 


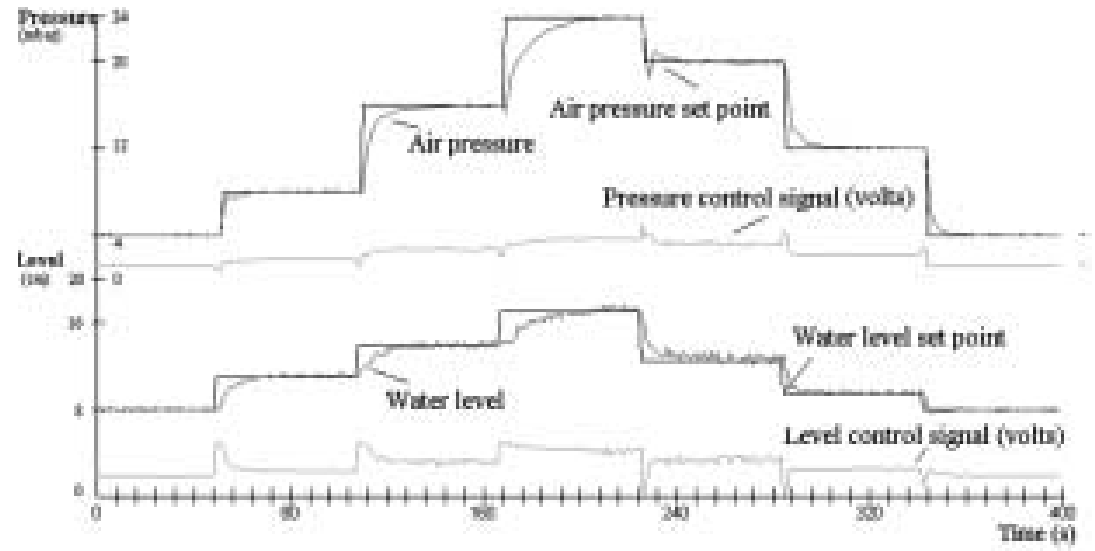

(a)

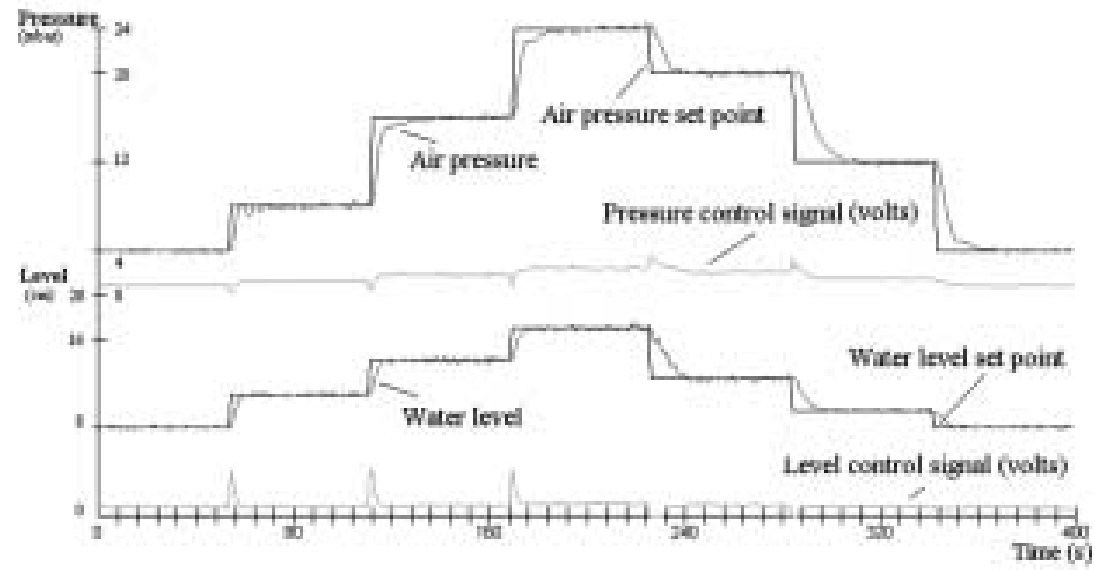

(b)

Fig. 7. Water level and air pressure coupled direct adaptive fuzzy control (a) normal plant conditions, (b) reduced outlets' throughput conditions.

\section{Conclusions}

- The adaptive fuzzy control methods and their learning and adaptation strategies are offered for the control of nonlinear and time-varying plant. Uncoupled adaptive fuzzy controllers perform well when controlling the time-varying plant in steady states but perform large air pressure overshoots during the transient states.

- To improve the performance of the air pressure control the coupled direct adaptive air pressure fuzzy controller is synthesized. The air pressure controller's output is calculated taking into consideration the water level. It is experimentally proved, 

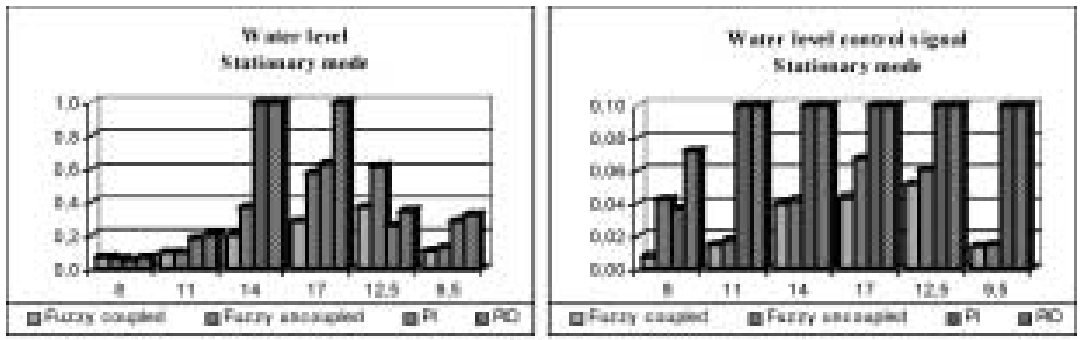

(a)
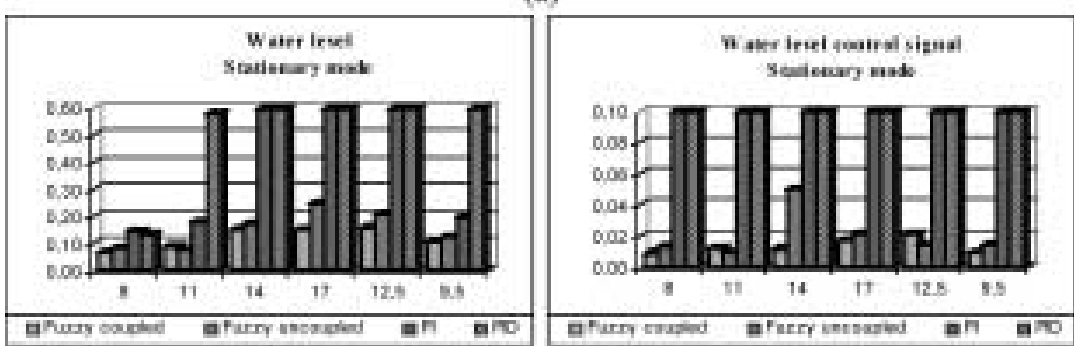

(b)
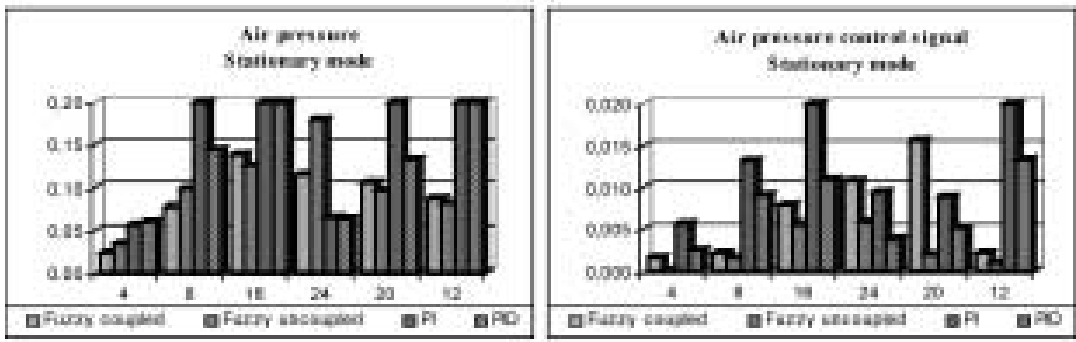

(c)
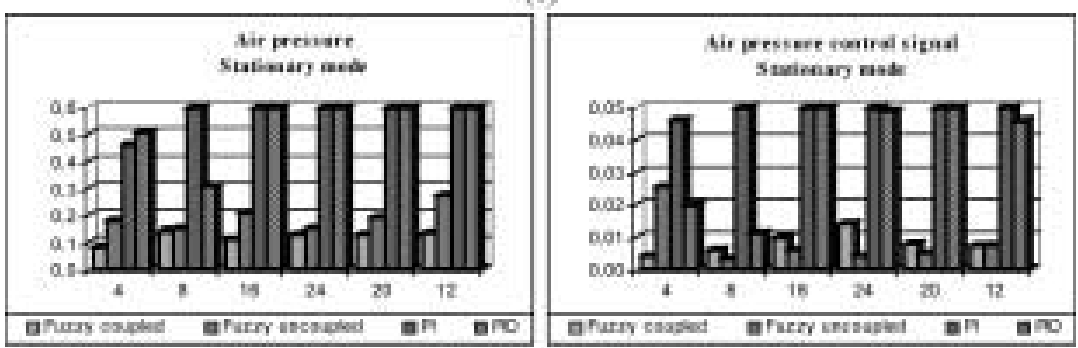

(d)

Fig. 8. Standard deviations (a), (c) normal plant conditions, (b), (d) reduced outlets' throughput conditions.

that coupled direct adaptive fuzzy control method enhances the plant's overall performance.

- Coupled adaptive air pressure fuzzy controller highly reduces the overshoots that were typical of the air pressure uncoupled control. The coupled adaptive air pressure fuzzy controller controls the air pressure with smaller actuating errors, if compared to the uncoupled air pressure fuzzy controllers, and at the same time reduces 
the water level actuating errors too, because the processes are strongly related to each other.

- The efficiency and advantage of the coupled adaptive fuzzy control methods over the uncoupled adaptive fuzzy control methods is experimentally proved, controlling the time-varying nonlinear plant under different working conditions.

- The overall control of the nonlinear plant is best achieved when the coupled adaptive fuzzy controller is used for the air pressure control and the uncoupled adaptive fuzzy controller is used for the water level control. This is because the coupled adaptive water level fuzzy controller does not evidently improve the control of the water level, the process that has much slower dynamics than the air pressure process.

\section{References}

Abonyi, J. (2003). Fuzzy Model Identification for Control.

Chen, G., and T.T. Pham (2001). Introduction to Fuzzy Sets, Fuzzy Logic, and Fuzzy Control Systems. CRC Press, New York.

Driankov, D., and R. Palm (1998). Advances in Fuzzy Control. Physica-Verlag Heidelberg, New York.

Kaminskas, V., and R. Liutkevičius (2002a). Fuzzy control of nonlinear plant. Information Technology and Control, 2(23), 39-45.

Kaminskas, V., and R. Liutkevičius (2002b). Adaptive fuzzy control of nonlinear plant with changing dynamics. Informatica, 13(3), 287-298.

Ogata, K. (1997). Modern Control Engineering. Prentice-Hall, New Jersey.

Passino, K.M., and S. Yurkovich (1998). Fuzzy Control. Addison Wesley, Menlo Park, California.

R. Liutkevičius was born on November 24, 1974. In 1996 he graduated from Faculty of Informatics, Vytautas Magnus University. In 1998 he received Master degree at the Faculty of Informatics, Vytautas Magnus University. His Doctoral dissertation, defended in 2003 , is in the field of adaptive fuzzy control systems. His research interest is in adaptive fuzzy control, system identification and modeling.

\section{Netiesinio proceso su kintančia dinamika adaptyvus dvimatis "fuzzy" valdymas}

\section{Raimundas LIUTKEVIČIUS}

Nagrinejami netiesinio objekto valdymo klausimai. Sudarytas "fuzzy" logikos pagrindu veikiantis adaptyvus dvimatis reguliatorius oro slègiui ir vandens lygiui valdyti. Eksperimentiškai parodytas jo pakankamas efektyvumas įvairiuose darbo režimuose. Dvimatis "fuzzy" reguliatorius palygintas su "fuzzy" reguliatoriumi, atskirai valdančiais vandens lygį ir oro slègi. 